\title{
The Teaching System Practical Research on Theory and Exercise Integration
}

\author{
Fangchun Jiang ${ }^{1, a,{ }^{*},}$ Yunfan $\mathrm{Lu}^{1, \mathrm{~b}}$ and Zhenjia Zhu ${ }^{1, \mathrm{c}}$ \\ ${ }^{1}$ shenzhen Institute of information technology, Longgang, Shenzhen, Guangdong, China \\ a06112061@bjtu.edu.cn, byunfan.lu@gmail.com, c824465@qq.com \\ ${ }^{*}$ Corresponding author
}

\begin{abstract}
Theory and exercise integrated teaching is a new teaching mode in vocational education institutes at present. From the aspects of teaching objective definition, teaching platform construction, teaching organization design and student assessment, this paper used MOOCs and SPOCs philosophy carried out the practical research on theory and exercise integration for teaching system design, and implemented the result on game software programming discipline, thus give conclusion.
\end{abstract}

Keywords: Theory and exercise integration, MOOCs, SPOCs, Game software.

\author{
理论实训一体化课程教学体系实践研究 \\ 蒋方纯 ${ }^{1, a,{ }^{*}}$, 陆云帆 ${ }^{2, b}$, 诸振家 ${ }^{3, c}$ \\ 1, 2, 3深圳信息职业技术学院, 龙岗, 深圳, 广东, 中国 \\ a06112061@bjtu.edu.cn, byunfan.lu@gmail.com, '824465@qq.com \\ *通讯作者
}

中文摘要. 理论实训一体化教学是目前职 业院校专业教学中探索创新的一种教学新 模式。本文从教学目标制定、教学平台搭建、 教学组织设计、学生成绩评定等方面, 借鉴 MOOCs与SPOCs思想, 结合游戏软件专业, 对理论实训一体化的课程教学体系进行了 实践研究，并做出了相应的分析。

关键词：理实一体化; MOOCs; SPOCs; 游 戏软件

\section{1. 引言}

“理实一体化”教学是目前职业院校专 业教学中探索创新的一种教学新模式。理论 知识围绕技能训练展开教学, “在做中学, 在学中做”; 既能实现理论与实践的完美结 合, 又能发挥学生的主体作用, 突出操作训 练; 既完成理论教学, 又实现对学生职业技 能的培养和提高, 做到 “教、学、做” 合一, 提高教学质量。

杜威 “做中学” 的实用主义教育体系 [1]、陶行知 “教学做合一” 的教育理论 [2] 及德国的 “行为引导型” 教学法[3]均为 “理 
实一体化” 教学模式提供了坚实了理论和实 践依据。教育部《关于全面提高高等职业教 育教学质量的若干意见》（教高[2006]16 号）[4]的文件精神要求在以工作过程为导 向的高职专业核心课程教学改革方面, 教学 活动应坚持融 “教、学、做” 为一体, 边做 边学边教, 有机融合, 将教师的作用从传授 为主转变为指导为主, 学生的角色从被动的 听为主转变为主动的练为主, 该文件为 “理 实一体化” 教学模式改革提供了政策依据。

专业是高职院校最基本的教育单位和 教学工作载体。专业建设是高职教育与社会 的契合点, 在高职教育中居于核心地位, 也 是高职教育办出特色的关键。专业建设的好 坏关系到高职院校服务区域经济建设和社 会发展的有效性, 也关系到高职院校的学生 的培养及毕业生的就业与创业, 其根本目的 是通过高职教学模式改革, 提高专业教学质 量。

本文以游戏软件专业为例，借鉴 MOOCs 与SPOCs思想, 进行理实一体化课 程教学体系的研究。

\section{2. 理实一体化体系内容}

理实一体化教学即理论实践一体化教 学法, 就是整理融会教学环节, 打破理论课、 实验课和实训课的界限, 将某门课程的理论 教学、实践教学、生产、技术服务融于一体, 把培养学生职业能力的理论与实践相结合 的教学作为一个整体考虑。单独制定教学计 划与大纲, 教学场所直接安排在实验室或实 训车间, 来完成某个教学目标和教学任务。 学生边学边做, 理论和实践交替进行, 突出 学生动手能力和专业技能的培养, 充分调动 和激发学生学习兴趣。

这是一种全新的教学模式, 是最适合于 职业教育教学需要的, 是与现代企业实现 “零距离” 接轨, 培养高素质技能型人才的 需要。本文从教学目标制定、教学平台搭建、 教学组织设计、学生成绩评定四个方面构建 “理实一体化” 教学模式。

\section{1 教学目标制定}

在制定教学目标时, 首先, 对职业岗位 群进行界定; 其次, 对岗位工作进行细分;
最后, 确定细化后的岗位工作的标准, 并据 此制定教学目标。

理实一体化课程是以典型项目为载体, 集理论传授、现场观摩、实践操作、技能训 练于一体的教学模式课程, 它注重工作过程 的完整性,使学生获得结构完整的相关职业 技能和职业体验, 从而促进学生职业素养的 养成。

高职教育能力观认为, 不仅要培养学生 专业能力, 即具备职业所需的专业理论基础 和操作技能, 更要重视其方法能力, 即具备 职业所需的工作方法和学习方法, 以及社会 能力, 即具备职业所需的行为规范和价值观 念的培养, 协助学生获得可持续发展能力。 所以, 应该先系统分析专业学生所应具有的 专业能力、方法能力、社会能力, 为教学目 标制定提供依据。

\section{2 教学平台搭建}

课程体系包括课程结构和课程内容两 个方面。课程结构应在 “三段式”重构为“两 段式” 的基础上, 课程内容也要由 “理论课” 和 “实践课” 向 “一体化课程” 转换, 构建 一体化的教学平台。

在一体化的教学工作场所中, 教师在讲 解理论知识同时, 也要使用相关的教学设 备, 配合教学素材进行实地演练; 学生在听 教师讲授专业理论同时, 也随同专业教师进 行实务操作。显然, 这样的教学平台有利于 专业学生在实践中体会理论, 并及时将所学 理论用于指导实践, 势必会大大提升其学习 兴趣与效率。

课程内容一体化的另一具重点是教材 一体化, 把知识性教材与技能性教材融为一 体, 形成一体化教材和课程, 是实施一体化 教学的基础。

\section{3 教学组织设计}

在教学组织设计时, 要单独制定教学计 划与大纲，构建职业能力整体培养目标体 系, 通过各个教学环节的落实来保证整体目 标的实现。

学习领域同岗位群中岗位工作是一一 对应的关系, 通过系列学习领域的完成, 最 终使得人才培养目标得以实现。在开展各学 习领域时, 可以根据其包含的内容, 将其分 
解为若干个学习情景, 每个学习情景都基于 一个完整工作过程, 并在具体任务导向下走 向结束, 最终完成一次教学过程。当一次教 学过程结束之后, 学生职业能力得到了一个 提升。

\section{4 学生成绩评定}

“理实一体化”教学模式下的学生成绩 评定也势必要进行根本性变革, 将基于 “全 面发展的能力观” 构建新的学生成绩评价体 系, 包括专业能力、方法能力、社会能力三 个大的方面。

课程评价是课程实施过程中的重要环 节, 课程评价体系会直接影响学生的学习积 极性和教学效果, 而传统的课程评价体系在 一定程度上限制了理实一体化课程的改革, 与现代职业教育倡导的 “以人为本” “全面 发展” 理念产生矛盾, 因此, 构建科学合理系 统的评价体系是保障理实一体化课程教学 效果的核心。

\section{3. 实现方式}

本研究既采用传统的实体教学方式, 即 教师面对面进行教学的方式, 又借鉴网络的 教学方法与手段, 主要是MOOCs与SPOCs 的教学方式, 把三者结合在一起。

MOOCs 是大规模开放在线课程, M是 Massive（大规模）， O 是Open（开放）， 第二个字母 $\mathrm{O}$ 是Online (在线), $\mathrm{C}$ 是Courses (课程)。该种教学方式是在网络上可以教 授大批学生, 便于课程的推广与普及, 但教 师参与的程度很降。一般来说, 学生观看简 短的讲课影片, 然后完成作业, 由机器或其 他学生批改, 缺少了面对教师的交流与讨 论, 直接面对面的互动性差 [5]。

SPOCs 是小规模私人在线课程, $\mathrm{S}$ 是 Small (小规模), $\mathrm{P}$ 是Private (私人), $\mathrm{O}$ 是Online (在线), $\mathrm{C}$ 是Courses (课程)。 该种教学方式改进了MOOCs教学方式在面 对面互动性方面的缺点, 课程以“因材施教、 因才求教” 为理念, 通过线上、线下多种学 习形式, 作为主体的学生和作为讲授的教师 实现教学相长[6]。

通过多种教学方式的结合, 发挥每种教 学方式的优点, 有些学习内容面对面讲授,
有些内容个性化学习指导, 有些内容完全由 学生自主学习与交流。利用现代信息技术的 特点, 构建符合现在学生学习需求的教学与 学习环境。

\section{4. 实践分析}

在上述研究的基础上, 以游戏软件专业 为例, 进行了实践研究。游戏软件专业课程 关系，如图1所示。

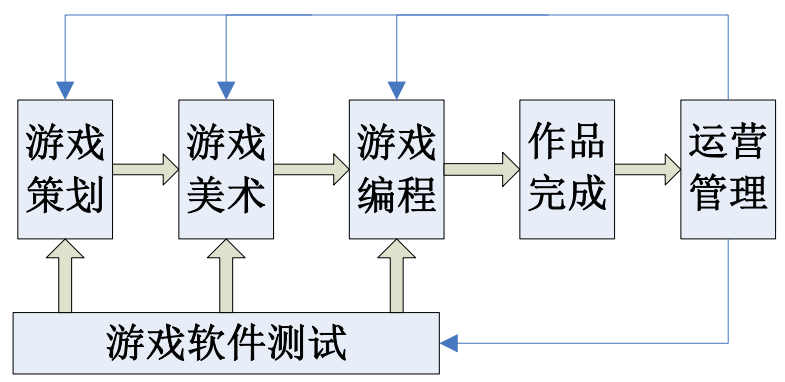

图1 游戏软件专业课程关系图

根据上述关系可以看出, 整个专业的教 学要做到一体化。同时, 每门课程的教学要 一体化。下面以《游戏策划与架构》课程为 例, 进行分析。

该门课程需要思想创新, 思维活跃, 所 以目前课堂教学管理方法有些僵化。不管学 生是否喜欢、是否愿意, 一律要求学生在规 定的时间内到规定的地点上课, 并实行严格 的课堂出勤管理制度。大学生的生理、心理 都比中小学生成熟, 该门课程的学习应当追 求学习方式和学习形式的多样化, 不应仅仅 局限于课堂教学。在教师统一指导下的学习 自由, 可以解决上述的一些不足。该门课程 的学习自由体现在以下几个方面: 小组成员 组合自由; 策划主题、情节的选定自由; 交 流讨论自由; 学习的时间相对自由; 学习的 地点相对自由。

按照通常工学结合的形式, 进行工学结 合要有企业的配合, 还需要有大段的时间 等, 目前实现起来比较困难。可以将工学结 合中 “工” 的要素引进行课程教学中, 在教 学过程中实现工学结合。在该门课程中“工” 的要素体现在以下几个方面: 在课程中加入 调研环节; 到游戏开发企业去学习策划的技 巧; 组织有关参观, 学习创意, 融入到策划 案中; 利用课余时间到有关企业去兼职。 
根据每个学生的具体学习水平和学习 进展情况, 提供个性化的学习内容、素材与 要求, 实现个性化理实一体化教学。

\section{5. 结束语}

理实一体化教学适应职业教育教学的 要求, 能够实现教育教学的基本目标。通过 在实际教学过程中加以改进, 教学实践不断 丰富理实一体化教学的内涵, 一定会提高职 业教育教学质量。

本研究成果, 不仅可供游戏软件专业参 考使用, 也可为其它专业参考使用, 尤其可 以利用现有的很多的课程网站, 借助 MOOCs 与SPOCs思想, 结合多种教学方式 与方法, 提升教学效果。

本项目研究具有一定的借鉴作用。

\section{致谢}

本文为深圳市教育科学规划课题《理论 实训一体化课程教学体系研究》 (2014, gh004)的研究成果之一。“十二五” 规划教 育部重点课题《非物质文化遗产校园传承研 究》子课题《校园非物质文化遗产成果展示 策略研究》（FY7Q006）研究成果之一。

\section{References}

[1] Zhonghui Shan, The exploration of modern education: Dewey's and practical education philosophy, People's Education Press,2002.

[2] Xingzhi Tao, Teach, Learn, Do all in one, Comprehensive practice activities research, vol.6, pp.22-31,2013.

[3] Dongsheng Zhang, Jin Deng, Humble opinion on German vocational education's 'Behavior oriented teaching method', Neijiang ploy-technical college academic journal, vol.3, pp.21-24,2009.

[4] Ministry of Education, "Multiple decisions on full enhancement on high vocational education quality" ([2006]No.16), http://www.tech.net.cn .

[5] Li Dong, Academic research of economics management discipline based on "MOOCs+face to face class", China education informatization, vol.345,pp.81-85,2015.

[6] Tsinghua University initial MBA C-SPOCs course, http://edu.qq.com. 